\title{
A INFLUÊNCIA DE FATORES SOCIAIS NA LINGUAGEM DE ADOLESCENTES PRIVADOS DE LIBERDADE
}

\author{
The influence of social factors in the language of private freedom adolescents
}

\author{
Rodrigo Mazer Etto' \\ Valeska Gracioso Carlos ${ }^{2}$
}

\section{RESUMO}

Este trabalho investigou a linguagem utilizada por adolescentes internos do Centro de Socioeducação de Ponta Grossa e teve por objetivos verificar a influência dos fatores sociais 'nível de escolaridade', 'convívio' e 'tempo de internação' do falante no uso exclusivo de uma variedade linguística caracterizada pela presença de palavras com sentido figurado, e identificar a possível dicionarização dos termos coletados, comparando o significado contido no dicionário com o sentido dado aos termos pelos entrevistados. Esta pesquisa realizou-se através da aplicação de entrevistas semiestruturadas a oito adolescentes internos do CENSE de Ponta Grossa. A análise dos fatores sociais possibilitou constatar que as duas variáveis que representaram cada um dos três fatores sociais apresentaram alguns termos e expressões, utilizadas exclusivamente, pertencentes ao vocabulário gírio. Dos 260 termos obtidos na etapa de coleta de dados, 156 não constam no referido dicionário; 64 constam no dicionário com sentido diverso do utilizado pelos informantes e 40 estão dicionarizados com o mesmo sentido. As investigações entre tal linguagem e fatores extralinguísticos podem contribuir para a compreensão do universo vocabular desses adolescentes e para os estudos sociolinguísticos, no sentido de possibilitar a criação de ferramentas pedagógicas que auxiliem tanto o processo de ensinoaprendizagem escolar dos adolescentes em conflito, quanto a desconstrução do preconceito linguístico, que reforça a marginalização desses adolescentes.

Palavras-chave: Variação linguística. Fatores sociais. Privação de liberdade.

\section{ABSTRACT}

This study investigated the language used by internal adolescents of the Ponta Grossa Socioeducation Center and had as objectives to verify the influence of social factors 'level of schooling', 'conviviality' and 'length of stay' of the speaker in the exclusive use of a linguistic variety characterized by the presence of words with figurative meaning, and to identify the possible dictionary of the terms collected, comparing the meaning contained in the dictionary with the meaning given to the terms by the interviewees. This research was carried out through the application of semi-structured interviews to eight internal adolescents of the CENSE of Ponta Grossa. The analysis of social factors made it possible to verify that the two variables that represented each of the three social factors presented some terms

\footnotetext{
1 Mestre em Estudos da Linguagem no Programa de Pós-Graduação em Estudos da Linguagem da Universidade Estadual de Ponta Grossa, Ponta Grossa, Brasil. E-mail: etto.rodrigo@gmail.com.

2 Professora Adjunda da Universidade Estadual de Ponta Grossa, Ponta Grossa, Brasil. E-mail: vgracioso@uol.com.br.
} 
and expressions, used exclusively, belonging to the gyrian vocabulary. Of the 260 terms obtained in the data collection stage, 156 are not included in the dictionary; 64 are in the dictionary with a different meaning from that used by informants, and 40 are dictionaries with the same meaning. The investigations between such language and extralinguistic factors can contribute to the understanding of the vocabulary universe of these adolescents and to the sociolinguistic studies, in the sense of enabling the creation of pedagogical tools that help both the teaching-learning process of the adolescents in conflict, deconstruction of linguistic prejudice, which reinforces the marginalization of these adolescents.

Keywords: Linguistic variation. Social factors. Deprivation of liberty

\section{INTRODUÇÃO}

Considerada como a essência da sociedade, é inconcebível imaginar um sujeito social sem a linguagem, pois esta é um elo entre o homem e o meio social em que vive, ou seja, entre o homem e ele mesmo. Faraco (1985, p.12) comenta que "a vida social, em todas as suas dimensões, possui práticas de linguagens diferentes e privilegia algumas em detrimento de outras, gerando, dessa forma, valores e atitudes". Os grupos minoritários, marginalizados socialmente, também produzirão diferentes falas, pois o conceito de sociedade envolve tanto o que é socialmente aceito, como aquilo que não o é.

Nesse sentido, a Sociolinguística, como ciência humana, analisa a linguagem em sua totalidade e não se condiciona ao que é ou não aceito socialmente. Para essa área de estudos linguísticos, as relações entre língua e sociedade são interdependentes, o que permite observar como as comunidades falantes articulam linguisticamente sua realidade, levando em conta sua cultura, condição social e forma de ver o mundo, visto que, para a Sociolinguística, as mudanças que ocorrem nos variados usos da linguagem decorrem de fatores internos ao sistema linguístico e de fatores externos. Logo, observar a linguagem dos indivíduos que compõem a sociedade possibilita perceber que há diferentes formas de linguagem, como é o caso da variedade linguística praticada por internos do CENSE de Ponta Grossa.

A variedade linguística utilizada por esses adolescentes está relacionada a fatores ambientais que caracterizam a instituição socioeducativa e a aspectos culturais do grupo social constituído pela população geral de internos. A constante sensação de estarem sendo 
A influencia de fatores sociais na linguagem de adolescentes privados de liberdade | Rodrigo Mazer Etto, Valeska, Gracioso Carlos

vigiados e segregados da sociedade, somado ao compartilhamento de regras paralelas e valores culturais peculiares (como, por exemplo, a adoção de uma postura contestadora dos valores defendidos pela sociedade mais ampla) favorecem a adoção de uma variedade linguística que permite que o falante entenda e seja entendido pelos integrantes do grupo ao qual faz parte, possibilitando a criação de uma identidade linguística que diferencie seu grupo dos demais grupos sociais. Em sua maioria, essa variação ocorre no plano semântico-lexical da língua e passa uma ideia de informalidade. São termos criados a partir da linguagem comum, mas com significados diferentes, com alteração do seu sentido original.

$\mathrm{O}$ interesse em estudar a linguagem praticada por adolescentes em regime de internação se deve principalmente a quatro fatores. O primeiro está relacionado ao fato do autor deste trabalho ter atuado profissionalmente como agente de segurança penitenciária durante 17 anos em uma unidade prisional paulista, cujas características ambientais como a privação de liberdade, a restrição de circulação e o contato forçado entre indivíduos com históricos de vida ligados à violência influenciam no modo como os indivíduos em regime de privação de liberdade veem o mundo, se comportam e no modo como exprimem seus valores e ideais através da linguagem.

Durante o período em que foi exercida tal atribuição profissional, a observação e a interação com os sentenciados permitiram constatar que um maior ou menor período de tempo em contato com a população carcerária influenciava no modo como os sentenciados se comunicavam, no sentido de um maior ou menor uso da variedade gíria, o que remete à relação defendida por Sapir ([1921] 1971) entre ambiente, linguagem e cultura.

A segunda motivação está ligada ao aumento da população carcerária brasileira que, segundo o mais recente Levantamento Nacional de Informações Penitenciárias (BRASIL, 2017), já atingiu a marca de 726.712 presos, a terceira maior do mundo, com um aumento de $707 \%$ se comparado ao ano de 1990. O mesmo documento concluiu que mais da metade dos adultos condenados já cumpriram medidas socioeducativas de internação na adolescência. 
A influencia de fatores sociais na linguagem de adolescentes privados de liberdade | Rodrigo Mazer Etto, Valeska Gracioso Carlos

O terceiro fator que estimulou a realização dessa pesquisa é o crescente número de adolescentes cumprindo medidas socioeducativas privativas de liberdade. De acordo com o último Levantamento Anual do SINASE - Sistema Nacional de Atendimento Socioeducativo (BRASIL, 2015a), em 2014, 23.066 adolescentes se encontravam cumprindo medidas socioeducativas privativas de liberdade; em 2016 esse número subiu para 58.079, segundo os dados do Cadastro Nacional de Adolescentes em Conflito (BRASIL, 2016).

E a quarta motivação relaciona-se com o fato dos adolescentes serem mais propensos à mudança que os adultos, visto que a adolescência, fase que marca a transição entre a infância e a idade adulta, é caracterizada por transformações físicas, psicológicas e sociais, exigindo do adolescente uma mudança de comportamento, dentre eles o linguístico, e a aquisição de competências que possibilitem seu futuro ingresso na fase adulta (ERIKSON, 1994).

A escolha em realizar esta pesquisa na área da sociolinguística justifica-se em virtude da evidente correlação entre práticas linguísticas e comunidades de falantes, dado que toda "língua falada está totalmente inserida e interligada à sociedade. Não há sociedade sem língua e nem língua sem uma sociedade para que esta se manifeste" (TARALLO, 2003, p. 19).

Tendo como sustentação teórico-metodológica a Sociolinguística Variacionista (WEINREICH, LABOV; HERZOG, [1968] 2006), também conhecida como Teoria da Variação e Mudança Linguística, cujo princípio básico é a relação entre língua e sociedade e o principal objetivo é o estudo das regras variáveis, este trabalho, através da aplicação de entrevistas semiestruturadas, buscou compreender a sistematicidade da variedade linguística praticada por adolescentes em cumprimento de medidas socioeducativas de internação, na tentativa de analisar a influência de fatores extralinguísticos como nível de escolaridade, convivio e tempo de internação do falante no uso específico dessa linguagem.

Sendo de natureza qualitativa, a presente pesquisa foi realizada através de uma perspectiva etnográfica, baseada na observação, descrição e NORUS | vol. $6, n^{\circ} 9$ | p. 343-375 | Jan/Jul/2018 
A influencia de fatores sociais na linguagem de adolescentes privados de liberdade | Rodrigo Mazer Etto, Valeska, Gracioso Carlos

análise de fatores socioculturais em relação aos fenômenos linguísticos, uma vez que esse método permite estudar descritivamente aspectos socioculturais de uma comunidade de falantes. A abordagem qualitativa, por possibilitar a imersão do pesquisador na comunidade estudada, se mostrou metodologicamente eficaz, pois o mesmo teve, como fonte direta de dados, o ambiente sociocultural do grupo de falantes em que se encontrava integrado.

Dessa forma, este artigo se divide em três partes.

A primeira parte discorrerá sobre a fundamentação teórica utilizada. Considerando que o código linguístico praticado pelos internos do CENSE Centro de Socioeducação de Ponta Grossa - reflete os aspectos ambientais da instituição e socioculturais dos adolescentes internos, foram utilizados os aportes teóricos de Sapir ([1921] 1971) e Coelho e Mesquita (2013) para tratar da relação entre linguagem, cultura e ambiente. Para abordar o fenômeno da variação linguística foram utilizados os apontamentos de Preti (1984) e Faraco (2008).

A segunda parte abordará a metodologia utilizada na pesquisa, como a abordagem qualitativa (FLICK, 2013), a etnografia (LOPES, 2003) e os aportes teóricos da Sociolinguística Variacionista (LABOV, [1972] 2008).

A terceira parte trará a análise da relação entre os usos linguísticos exclusivos dos entrevistados e os fatores sociais: 'tempo de internação', 'grau de escolarização' e 'possibilidade de convivio'. Também será analisada a presença ou ausência dos itens coletados no dicionário Houaiss (2011) no intuito de verificar se os sentidos dos itens coletados conferem com os significados contidos no referido dicionário.

\section{REFERENCIAL TEÓRICO}

\section{I Linguagem, cultura e ambiente}

Através da linguagem o homem pode comunicar-se, influenciar seus semelhantes, exteriorizar seus sentimentos e pensamentos, conhecer outras culturas e revelar a sua, ou seja, através de seus usos linguísticos, o homem constitui-se como ser social, político e ideológico, visto que, como aponta Bakhtin (2006, p. 36), "a palavra é o fenômeno ideológico por excelência [...] o modo mais puro e sensivel da relação social". 
Dessa forma, a linguagem possibilita a identificação de grupos sociais, pois tem o poder de expressar a realidade da comunidade que a utiliza, permitindo que essa comunidade transmita sua cultura. Há, portanto, uma relação clara entre linguagem e cultura, sendo que, para se estudar o comportamento linguístico de um grupo social, é preciso observar a cultura, os hábitos e as peculiaridades que envolvem tal grupo.

Assim, o presente estudo, envolvendo adolescentes em regime de privação de liberdade, revelou importantes aspectos linguísticos desse grupo social, pois as características ambientais a que estão sujeitos, como a restrição de circulação, o convivio forçado com outros internos e a constante vigilância, somadas às características socioculturais dos internos, como o afastamento familiar e social, históricos de vida ligados à violência, obediência às regras paralelas da população geral de internos e a contestação e violação das regras de boa convivência defendidas pela sociedade civil, influenciam no modo como esses adolescentes veem o mundo, se comportam, e na maneira como exprimem seus valores e ideais através da linguagem. Tal influência cultural e ambiental encontra respaldo em Coelho e Mesquita (2013, p. 26), quando estes apontam que a linguagem não é somente um mero conjunto de signos e regras de combinação desses signos, "haja vista ser atravessada por aspectos da ordem do fisico, do sociocultural, do psicológico e do linguístico".

A linguagem praticada pelos internos do CENSE reflete muitos aspectos culturais que determinam o comportamento dos adolescentes, como, por exemplo, o cuidado que os adolescentes devem ter no período da refeição: se algum interno quiser conversar, ele deve usar a frase 'Licença pra falar', e se precisar utilizar o banheiro, deve pedir autorização aos demais através do uso da frase 'Licença pra usar o boi', visto que o horário das refeições é considerado ‘sagrado' pelos mesmos.

Considerando a cultura como "o complexo de valores, costumes, crenças e práticas que constituem o modo de vida de um grupo específico" (EAGLETON, 2005, p. 55), outro aspecto que revela a relação entre cultura e usos linguísticos, presente nesse ambiente institucional, é a tradição da população de internos de submeter um adolescente recém-chegado a um 
A influencia de fatores sociais na linguagem de adolescentes privados de liberdade | Rodrigo Mazer Etto, Valeska, Gracioso Carlos

interrogatório, na intenção de obter informações sobre seu passado e sobre possiveis dividas e desavenças com outros internos, sendo que, o conhecimento ou desconhecimento da linguagem utilizada pelos internos pode auxiliar ou prejudicar o entendimento e os argumentos do novato que, após essa interpelação, se não apresentar condições de conviver com os demais, 'pede seguro' aos educadores, ou seja, é transferido para algum alojamento em que o convivio não é permitido, visando a preservação de sua integridade fisica.

O uso dessa variedade linguística pelos internos permite que eles se identifiquem uns com os outros através do compartilhamento de valores socioculturais comuns, o que permite inferir que língua e cultura estão relacionadas, visto que "é por meio da língua que a cultura se constrói e é difundida, e é também por meio dela que ocorrem os processos de identificação" (COELHO; MESQUITA, 2013, p. 2).

Dado o caráter etnográfico dessa pesquisa, é oportuno reforçar a existência de uma relação intrínseca entre cultura e língua, pois, sendo um ser social, o homem tem grande necessidade de

$$
\begin{aligned}
& \text { interagir com a realidade em que está circunscrito, pois necessita } \\
& \text { comunicar-se com o outro. Por meio desta comunicação, ele partilha } \\
& \text { sua visão de mundo, suas experiências, sentimentos, } \\
& \text { conhecimentos, enfim, sua cultura. Portanto, a língua de um grupo é } \\
& \text { parte de sua cultura. (COELHO; MESQUITA, 2013, p. 33) }
\end{aligned}
$$

Por fazer parte da cultura presente no CENSE, a linguagem praticada pelos internos é rapidamente assimilada pelos adolescentes recém-chegados, sendo que alguns já a praticavam antes de serem detidos e enviados à instituição, e outros adotam essa linguagem durante o cumprimento da medida socioeducativa, fato que confere com o posicionamento de Sapir (1971 [1921], p. 22), para quem a linguagem não é uma capacidade comunicativa herdada, mas sim uma função cultural que se assimila por meio de usos sociais, ou seja, a linguagem constitui-se em um completo sistema funcional relacionado à constituição psicobiofisica humana, e nas próprias palavras de Sapir, a linguagem "é um método puramente humano e não-instintivo de comunicação de ideias, emoções e desejos por meio de um sistema de símbolos voluntariamente produzidos". 
Considerando a influência do contexto ambiental nos usos linguísticos, para Sapir (1987 [1947], p. 44), o termo "ambiente" se refere às influências que independem da vontade dos indivíduos, como, e principalmente, as de caráter físico, embora "convém compreender no termo ambiente tanto os fatores físicos como os sociais".

O CENSE representou o ambiente físico e social que influenciou a variação linguística praticada pelos internos, sendo a restrição de circulação, a permanente vigilância, a segregação social e o convivio forçado entre indivíduos com históricos de vida ligados à violência as características mais marcantes dessa instituição fechada, pois, embora se constitua em um espaço não natural, por se tratar se uma invenção antropocultural, tal ambiente resulta em várias limitações aos adolescentes. A composição desse ambiente: vários 'xis' (termo relacionado eufemisticamente a celas), alojamentos, alambrados, grades de ferro, muros altos, torres e câmeras de vigilância, são os principais motivadores dos comportamentos sociais e linguísticos dos internos.

O autor reconhece essa influência ambiental e sociocultural através de três níveis de fala: o nível morfossintático - relativo aos processos de formação e classificação das palavras; o fonético-fonológico - referente ao sistema de sons que se operam para a construção de palavras; e o nível semântico-lexical - relacionado ao conteúdo ou assunto (SAPIR, [1947] 1987). O presente estudo teve como foco o terceiro nivel proposto por esse linguista, no intuito de possibilitar identificar o sentido do léxico utilizado pelos internos do Centro Socioeducativo (análise semântico-lexical).

Considerando a influência do ambiente físico e sociocultural nas escolhas lexicais, afirma Sapir:

o léxico completo de uma língua pode se considerar, na verdade, como o complexo inventário de todas as ideias, interesses e ocupações que açambarcam a atenção da comunidade, pois o léxico de uma língua é o que mais nitidamente reflete o ambiente físico e social dos falantes. (SAPIR, 1987 [1947], p. 45)

Portanto, estudar a linguagem dos internos do CENSE implica também resgatar sua cultura e levar em conta o contexto ambiental em que é praticada, considerando-se que essa variedade linguística concentra e 
A influencia de fatores sociais na linguagem de adolescentes privados de liberdade | Rodrigo Mazer Etto, Valeska, Gracioso Carlos

acumula as aquisições culturais que retratam a comunidade em que estão inseridos e, apesar de não se configurar em um outro idioma, principalmente por não possuir sintaxe própria, caracteriza-se como um vocabulário diferenciado, que reconhece e reflete o contexto ambiental e social no seu léxico.

\section{2 Variação Linguística}

A variedade linguística praticada pelos internos do CENSE também é conhecida como gíria de grupo, e consiste numa forma peculiar de expressão que se diferencia da variedade padrão, sobretudo no aspecto semânticolexical, em que as palavras adquirem outros sentidos, dificultando a compreensão de quem não pertence ao referido grupo.

Segundo Preti (1984, p. 23), um dos maiores pesquisadores desse tema, esse vocabulário surge em decorrência do isolamento social do indivíduo interno e indica reação e contestação aos valores e padrões socioculturais impostos pela ideologia da sociedade mais ampla, visto que, "falando diferente, estropiando a linguagem usual, ele agride o convencional, opõe-se ao uso aceito pela maioria, e deixa marcado seu conflito com a sociedade". Esse autor classifica essa linguagem em: gíria comum - aquela que migrou da condição de linguagem de grupo restrito para a linguagem comum da sociedade, e gíria de grupo - aquela praticada, restritamente, por integrantes de um grupo social específico.

Pela perspectiva de signo de grupo, essa variedade linguística pode ser definida como um vocabulário restrito aos internos que compartilham o mesmo grupo social - ligado à vida no crime e ao consequente cumprimento de medidas socioeducativas, sendo que o domínio do seu caráter secreto pode significar a inclusão do falante no referido grupo.

O caráter criptológico da gíria de grupo possibilita a constante renovação do seu vocabulário, que é usado como forma de identificação do falante para marcar seu conflito com a sociedade (PRETI, 1984). Essa posição coincide com o apontamento de Remenche (2003, p. 24), quando esta afirma que a gíria é "uma linguagem que utiliza palavras ou frases não 
convencionais que expressam coisa nova ou velha, através de uma nova forma de expressão".

Através de uma perspectiva sociolinguística, a presente pesquisa apresentou um interesse linguístico pelo caráter social dessa linguagem, visto que objetivou analisar de que forma alguns fatores sociais podem determinar ou influenciar a linguagem dos adolescentes internos do CENSE, em que foi traçado um caminho "partindo-se do próprio vocabulário recolhido, de suas variações, do estudo de suas áreas semânticas, dos processos morfológicos de sua formação, para chegar-se à compreensão das variantes socioculturais que o produziram" (PRETI, 1984, p. 13).

Essa diversidade de formas linguísticas dentro da Língua Portuguesa encontra respaldo em Faraco (2008), quando esse autor afirma que uma língua é constituída por um conjunto de variedades, não sendo apenas uma unidade da linguagem, mas uma entidade cultural e política. Essa posição confere com a definição de norma dada por Coseriu (1987, p. 74), que define essa expressão como aquela de "como se diz" e não a de "como se deve dizer". De acordo com esse pensamento, pode-se considerar norma como um conjunto de fatores linguísticos que caracterizam o modo como normalmente falam as pessoas de uma comunidade, e não regras que determinem como se deve falar (FARACO, 2008).

Vale a pena reforçar que a linguagem praticada pelos internos do CENSE é influenciada pelo contexto cultural e ambiental em que se localiza essa comunidade de falantes, determinando a posição social de seus integrantes, pois as variedades linguísticas nada mais são do que o reflexo da sociedade, onde esta possui uma variedade social, caracterizando então, o papel dos indivíduos e dividindo-os em grupos, classes (POSSENTI, 1997).

\section{METODOLOGIA DE PESQUISA}

A metodologia de pesquisa foi de natureza qualitativa, sendo realizada através da aplicação de uma entrevista narrativa e de um questionário semântico-lexical aos oito colaboradores, pois através desse método, "esperase que os participantes respondam às questões abertas espontaneamente e com suas próprias palavras" (FLICK, 2013, p. 23). 
A influencia de fatores sociais na linguagem de adolescentes privados de liberdade | Rodrigo Mazer Etto, Valeska, Gracioso Carlos

Assim, os resultados puderam ser mais precisos, o que confere certa importância à abordagem qualitativa, conforme aponta Lopes (2003) em seu trabalho intitulado "Narrativas das adolescentes em conflito com a Lei":

\begin{abstract}
é pela observação do comportamento que se descobrem as palavras escritas e faladas que serão estudadas pelo pesquisador. Não há preocupação com números, porcentagens e estatísticas. Importa o que o pesquisador observou e apreendeu em determinado grupo social. (LOPES, 2003, p. 34)
\end{abstract}

Esta pesquisa realizou-se através de uma perspectiva etnográfica, pois, apesar de não apresentar um período de tempo em campo muito extenso, baseou-se nos pressupostos metodológicos da etnografia, o que permitiu uma análise descritiva de muitos aspectos socioculturais, como os valores, as crenças e as regras paralelas que regem o comportamento dos integrantes desse grupo, os quais se estabelecem através de determinadas posturas e da adoção de uma variedade linguística caracterizada pela presença de palavras com sentido figurado.

Para a etapa de coleta de dados, foram utilizados alguns recursos tecnológicos e metodológicos que caracterizam uma pesquisa sociolinguística, como gravador de som, blocos de papel, caneta representando os primeiros, e a observação, gravação das entrevistas e registros escritos - representando os segundos, pois, através dessa perspectiva, é possivel "que a gente conheça o estado atual, real da língua, como ela é de fato usada pelos falantes, por meio da frequência de uso da variante X e da variante Y" (BAGNO, 2007, p. 51).

Um problema metodológico clássico da Teoria da Variação e Mudança é que a observação sistemática da fala (necessária para a obtenção dos dados) por si só provoca, no informante, um nível de automonitoramento da fala maior que o mínimo - ou seja, um afastamento da fala natural. Esse problema ficou conhecido como "paradoxo do observador" (LABOV, [1972] 2008 , p. 245) e, se desconsiderado, pode influenciar negativamente a coleta de dados linguísticos.

Dessa forma, o método de coleta de dados utilizado procurou superar, da forma mais eficiente possivel, o efeito negativo do paradoxo do observador, considerando que o mero contato com o informante já seja um 
empecilho para a obtenção natural de sua fala. Então, optou-se pela entrevista individual com cada adolescente - gênero preferido pela Sociolinguística para a etapa de coleta de dados, por garantir uma amostra longa de fala com pouca interferência de ruídos.

Dentre os cuidados metodológicos utilizados, os entrevistados foram estimulados a descrever episódios marcantes vivenciados, para que se envolvessem emocionalmente nas lembranças e desviassem a atenção no monitoramento de sua própria fala; tomou-se o cuidado de "evitar usar a palavra língua" e o pesquisador teve que "representar o papel de aprendizinteressado na comunidade de falantes e em seus problemas e peculiaridades" (TARALLO, 2003, p. 21-22).

A natureza etnográfica do trabalho exigiu do pesquisador responsável pela coleta dos dados uma habilidade para contornar a desconfiança inicial dos entrevistados, pois representava um elemento externo ao cotidiano vivido pelos internos. Então, logo no início da aplicação das entrevistas os internos foram cumprimentados amistosamente com aperto de mão e com alguns termos pertencentes à variedade linguística por eles utilizada e que já eram do conhecimento do entrevistador - como os termos 'véio', 'mano' e 'expressões como 'tô ligado' e 'issumemo', com a intenção de facilitar a interação e "não ser identificado como representante de nenhum grupo específico", conforme recomendam Ludke e André (1986, p. 17). É importante relatar que, da mesma forma que ocorre com os sentenciados em uma unidade prisional, os adolescentes internos relutam em cumprimenta com aperto de mão pessoas alheias à instituição, pois o código moral paralelo que também rege seus comportamentos, não permite essa aproximação.

Também lhes foi explicado que uma das finalidades da pesquisa era conhecer o dia a dia dos internos do CENSE, sendo que essa justificativa aliada à leitura do termo de consentimento do pesquisador responsável, que garante o sigilo da identidade dos informantes, sob pena do pesquisador ter de responder criminalmente pelo não cumprimento das recomendações contidas nesse documento, permitiram estabelecer uma relação de maior confiança com os participantes da pesquisa. 
A influencia de fatores sociais na linguagem de adolescentes privados de liberdade | Rodrigo Mazer Etto, Valeska, Gracioso Carlos

O roteiro de perguntas da entrevista narrativa foi dividido em cinco tópicos: infância, família, escolaridade, cotidiano do ambiente socioeducativo e linguagem, e foi formulado no intuito de aproximar o informante do entrevistador, considerando-se que indivíduos privados de liberdade se sentem mais à vontade quando conversam sobre determinados temas como família, futebol, namoro etc. Nesse sentido, afirma Tarallo:

\begin{abstract}
A narrativa de experiência pessoal é a mina de ouro que o pesquisador sociolinguista procura. Ao narrar suas experiências pessoais mais envolventes, ao colocá-las no gênero narrativa, o informantes desvencilha-se praticamente de qualquer preocupação com a forma. (TARALLO, 2003, p. 23)
\end{abstract}

A aplicação do questionário semântico-lexical deu à segunda etapa de entrevista um caráter de pesquisa sistemática, em que os informantes foram convidados a responder qual variedade linguística (gíria) correspondia aos termos que lhes eram apresentados, com o propósito de verificar a produtividade dos vocábulos que constituem a linguagem por eles utilizada.

Como o objetivo principal dessa pesquisa foi estudar qualitativamente o comportamento linguístico dos oito colaboradores de acordo com os três fatores sociais escolhidos, cada um desses três fatores sociais foi subdividido em duas variáveis linguísticas, também conhecidas como "indices de enquadramento social" (LABOV, [1972] 2001, p. 38). Dessa forma, os oito adolescentes foram divididos de acordo com as seis variáveis sociais em que se enquadravam: quatro internos que estavam cumprindo medidas de internação de até seis meses e quatro que estavam cumprindo tais medidas por mais de seis meses; quatro que possuíam nível de escolarização de até o sexto ano do E.F. e quatro que tinham concluído anos posteriores; quatro internos lotados em alojamentos de convivio e quatro que residiam em alojamentos sem convivio.

O fator convivio foi subdividido nas variáveis 'com convivio' e 'sem convivio', sendo escolhidas em virtude da estrutura física do CENSE. Lá, os internos já submetidos à condenação judicial e os que mostrem condições de viver em conjunto são lotados em quatro alojamentos em que podem interagir entre si num espaço destinado a atividades educativas e de lazer. Os internos ainda não submetidos a tal condenação e os que não 
apresentam condições de viver em conjunto são lotados em outros quatro alojamentos, cuja estrutura física não permite a interação entre os alojados. Assim, o motivo dessa divisão é verificar se há diferenças de usos linguísticos com sentido figurado em decorrência do fator 'convívio', que foi considerado nesta pesquisa como um sinônimo do fator 'rede social', visto que os usos linguísticos das pessoas que convivem em grupo podem fornecer indícios do peso da variável 'rede social' sobre os usos linguísticos de um grupo (BORTONI-RICARDO, 2004).

Os índices de enquadramento social 'nível de escolarização de até o sexto ano do E. F.' - e 'nível de escolarização superior ao sexto ano do E. F.' foram elencados visando verificar do peso do fator 'grau de escolarização' na relação com o uso exclusivo de termos e expressões com sentido figurado, pois o comportamento linguístico de um indivíduo depende de muitas variáveis, inclusive do seu nível de escolaridade (VOTRE, 2004), que desempenha papel fundamental no domínio de uma variedade linguística e no uso de determinados vocábulos. Para Votre (2004) a escolaridade influencia muito a questão da fala, pois alunos com mais anos de estudo não possuem a mesma fala que os alunos com menos anos de escolaridade, ou seja, a fala de ambos terá diferentes variações devido ao nível de escolaridade e até mesmo de conhecimento linguístico e do sistema de sua língua.

A diretoria do CENSE informou que a média de períodos de tempo de internação cumprida pelos internos que comporta é de um ano. Assim, esse fator subdividiu-se nas variáveis 'tempo de internação de até seis meses' e 'tempo de internação superior a seis meses', e foram utilizadas, considerando-se que um maior ou menor período de tempo submetido às características físico-ambientais da instituição e ao contato com outros internos pode resultar em diferenças no comportamento linguístico do falante e, portanto, em diferentes frequências de uso da variedade linguística em estudo. Tendo em vista que alguns dos participantes dessa pesquisa já cumpriram medidas de internação em outras instituições socioeducativas do Estado do Paraná, para cálculo dessa variável, considerou-se como tempo de 
A influencia de fatores sociais na linguagem de adolescentes privados de liberdade | Rodrigo Mazer Etto, Valeska, Gracioso Carlos

internação a soma de todos os períodos de privação de liberdade já cumpridos pelos adolescentes.

\section{DISCUSSÃO E ANÁLISE}

A primeira analise consistiu em dividir os termos e expressões coletadas em nove campos conceituais, assim distribuídos:

Características atribuídas aos outros:

À pampa, Aliado, Areieiro, Atrasa-lado, Baba ovo, Borsa, Boy, Burrão, Cabuloso, Cagueta, Caçamba,Cagão, Chapado, Cheio de querer, Calçado, Calibrado, Carroça, Cobaia, Considerado, Coroa, De boa, Desacorçoado, Descalço, Desumilde, Doze-duque, Duas caras, Duque-treze, Em choque, Embalo, Falseane, Faraó, Flor, Função, Gambé, Gostar de se mostrar, Inocentão, Isqueiro,Jack, Crocodilo, Jurão, Ladrão, Madeireiro, Maluco, Mano, Maquinado, Mascão, Mina, Mocorongo, Morgado, Mula, Nóia, Novato, Peidão, Piolho, Pilantra, Retardado, Tá chapando, Tá suave, Tô de boa, Tô de cara, Tô de lara, Tô lesado, Tô no veneno, Tongo, Um-cinco-cinco, Zoador, Viado.

Sensações e ações praticadas:

Abraçar ideia, Adianto, Agá, Agachamento, Bater a blindada, Bolar ideia, Bronca, Caçar assunto, Cair com, Calçar o peito, Cambau, Cena, Chamar na humildade, Chapar com, Chocar, Chorar, Clarear, Condena, Correr com, Dar a letra, Dar atenção, Dar gesto, Dar ideia, Dar milho, Dar mio, Dar nome, Dar uma contenção, Dar uma mão, Dar um pega, Dar raio, Dar um rolê, Dar um tiro, Debater, De mil grau, Deixar falando, Desacordo, Desavença, Dormir na pedra, Encaixotar, Enquadrar, Estar azul, Estar de lança, Estar na alimentação, Estar ligado, Estar no sossego, Estrutural, Fazer a cabeça, Fazer a ponte, Fazer jogo, Fazer uma média, Fechar com alguém, Ficar na corda, Ficar no suíno, Guento, Jogar areia, Lance, Levar liga, Ligar, Magar, Mancada, Mandar um salve, Marretão, Medida disciplinar, Mocozar, Negar voz, Pagando ativa, Pagando dentária, Passar a visão, Passar o fone, Passar pano, Pegar pira, Procedimento, Revista, Sair no cinco, Tirar um descanso, Tirar uma brisa. 


\section{Objetos:}

Barca, Beca, Gancha, Bic, Brasa, Bobo, Buti, Campana, Calibre, Canhão, Cano, Catatau, Chorona, Coruja, Espiritique, Estampa, Estoque, Fire, Fute, Pelota, G 2, Prestobarba, Lambreta, Luna, Manta, Naifa, Oitão, Pano, Pena, Tinteira, Perna, Pipa, Pisante, Radinho, Ramera, Rolex, Rolon, Tela, Teresa, veste,.

\section{Expressões e termos gerais:}

Bagulho, Banca, Da hora, Fita, Fitinha, Fuja louco, Já era, Jamais, Licença com a palavra, Magro, Mudar de xis, Pegar beco,Por que você caiu?, Qual seu B.O.?, Quem você flagra na tua quebrada?, Sai fora !, Sua cara, Tá difícil, Tá tirando, Tem condições de fortalecer.

Locais do ambiente institucional:

Barraco, Bocuda, Boi, Contenção, Xis de castigo, Ducha, Externa, Jega, Latrô, Na rocha, Na tranca, Tatu, Ventana, Xis, Zoiúda .

\section{Alimentação:}

Blindada, Explosiva, Galeto, Graxa, Marrocos, Meia lua, Mínima, Meiota, Pá, Pazinha, Porva, Sadia, Sobre.

Partes do corpo:

Badalo, Boga, Cofre, Camito, Janja, Juba, Mâfins, Pinha.

\section{Drogas:}

Baseado, Beque, Botinho, Careto, Fininho, Fino, Farinha, Pó, Gole, Caiçara, Paieiro.

\section{Dinheiro:}

Cincão, Cisco, Deizão, Desco, Galo, Malote, Moeda, Garoupa, Onça, Peixe.

O gráfico a seguir ilustra a divisão dos termos e expressões coletadas segundo seus respectivos campos conceituais:

\section{Gráfico I - Campos semânticos}


A influencia de fatores sociais na linguagem de adolescentes privados de liberdade | Rodrigo Mazer Etto, Valeska, Gracioso Carlos

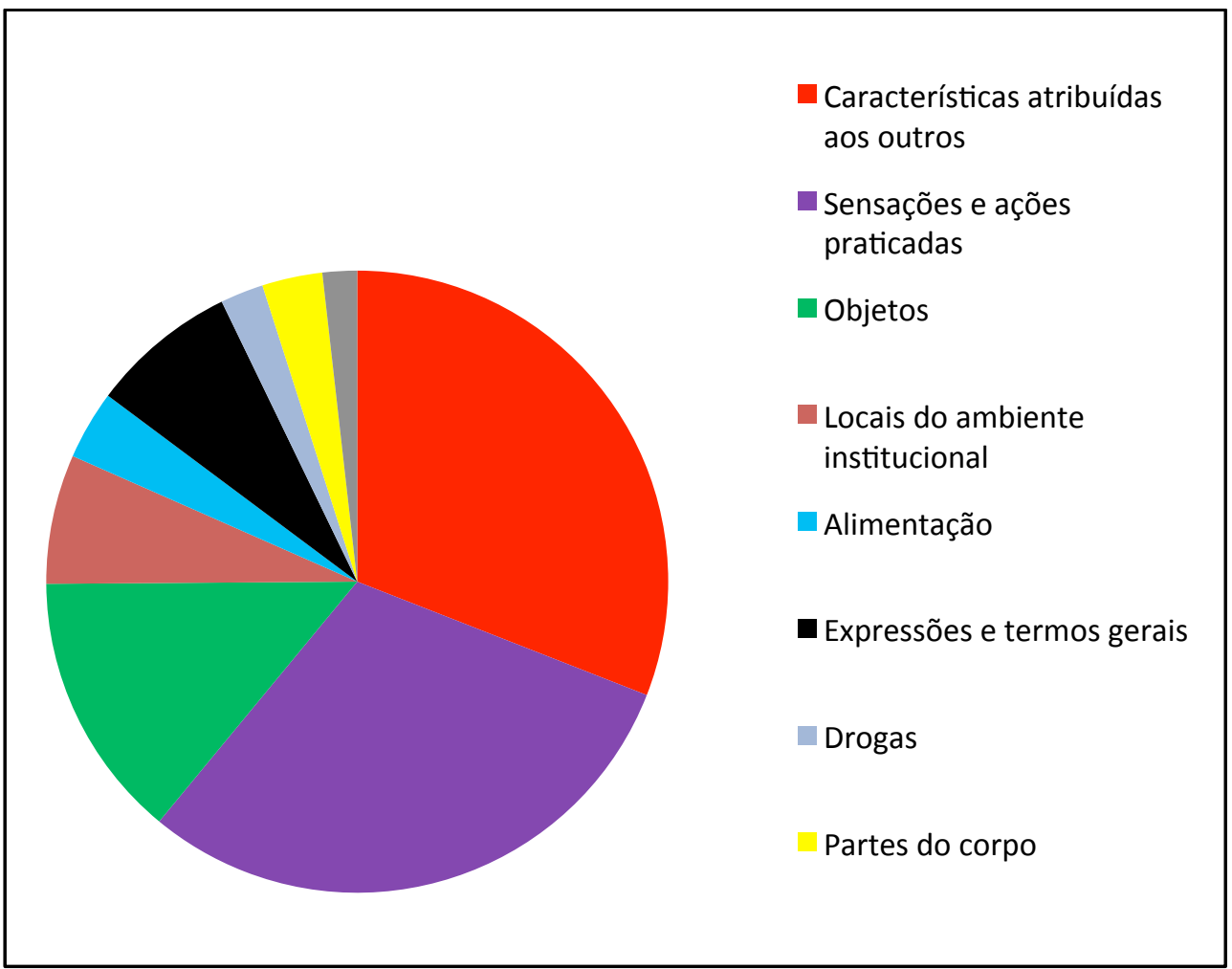

Fonte: Elaboração do autor

A análise dos dados teve como uma das suas bases a experiência adquirida por este pesquisador durante o exercício da função de agente de segurança penitenciária, fato que se apoia em Johnstone (2000, p. 98-104), quando este aponta que "atualmente os sociolinguistas vêm estudando o uso da linguagem pela gravação da fala, mas trazem também sua experiência de mundo como parte do conhecimento para analisar os dados".

Assim, o uso dessa linguagem, bem como a interpretação das crenças e atitudes dos seus falantes, foram analisadas, levando-se em conta a prévia experiência profissional adquirida em um contexto de privação de liberdade.

O questionário semântico-lexical baseou-se no estudo de Corrêa (2008), que realizou uma pesquisa sobre a linguagem de menores infratores sem seis unidades do CENSE do Estado do Paraná, localizadas em Foz do Iguaçu, Londrina e Curitiba.

Por ter sido realizada em instituições localizadas sem três cidades paranaenses e apresentar temática semelhante à da presente pesquisa, esse embasamento possibilitou a formulação de perguntas que fizessem parte da realidade vivida pelos internos, considerando-se, principalmente, o contexto regional (estadual) em que ambas as pesquisas foram realizadas. 
A aplicação e posterior análise desse questionário possibilitou a obtenção de 260 itens lexicais com sentido figurado. Destes, 156 não estão dicionarizados em Houaiss (2011), 64 itens estão dicionarizados com outro sentido no referido dicionário e 40 termos e expressões estão dicionarizados com o mesmo sentido dado pelos entrevistados.

Os 156 vocábulos e expressões que não se encontram dicionarizados o que representa mais da metade do total de itens obtidos (60\%), sinalizam que tais itens ainda preservam o caráter restrito e secreto dessa variedade linguística - a gíria de grupos ligados à marginalidade, que se caracteriza por sinalizar uma agressão ao convencional, atestando o conflito desse grupo social com a sociedade (PRETI, 1984).

Os 64 termos e expressões que se encontram dicionarizados em Houaiss (2011) com sentido diferente do utilizado pelos colaboradores também apontam que, apesar de constarem no referido dicionário, os sentidos dados a esses termos pelos colaboradores também mantém o caráter fechado e restrito dessa variedade linguística.

Os 40 termos e expressões dicionarizados com o mesmo sentido do usado pelos entrevistados apontam que tais itens lexicais já não apresentam o caráter restrito que distingue a gíria de grupo, visto que sua dicionarização e o consequente alcance pelas pessoas comuns indicam que "ao vulgarizarse para a grande comunidade assumindo a forma de uma gíria comum, de uso geral e não diferenciado, a gíria perde-se dentro dos amplos limites de um dialeto social popular, deixando de ser signo grupal" (PRETI, 1984, p. 3).

A dicionarização desses itens indica que o caráter secreto dessa variedade linguística é efêmero, uma vez que os vários estilos musicais, como o rap, o funk e o cinema nacional promovem, dia a dia, um alcance cada vez maior a essa linguagem.

O gráfico a seguir ilustra a dicionarização do corpus coletado: 
A influencia de fatores sociais na linguagem de adolescentes privados de liberdade | Rodrigo Mazer Etto, Valeska, Gracioso Carlos

\section{Gráfico 2 - Distribuição do corpus quanto à dicionarização}

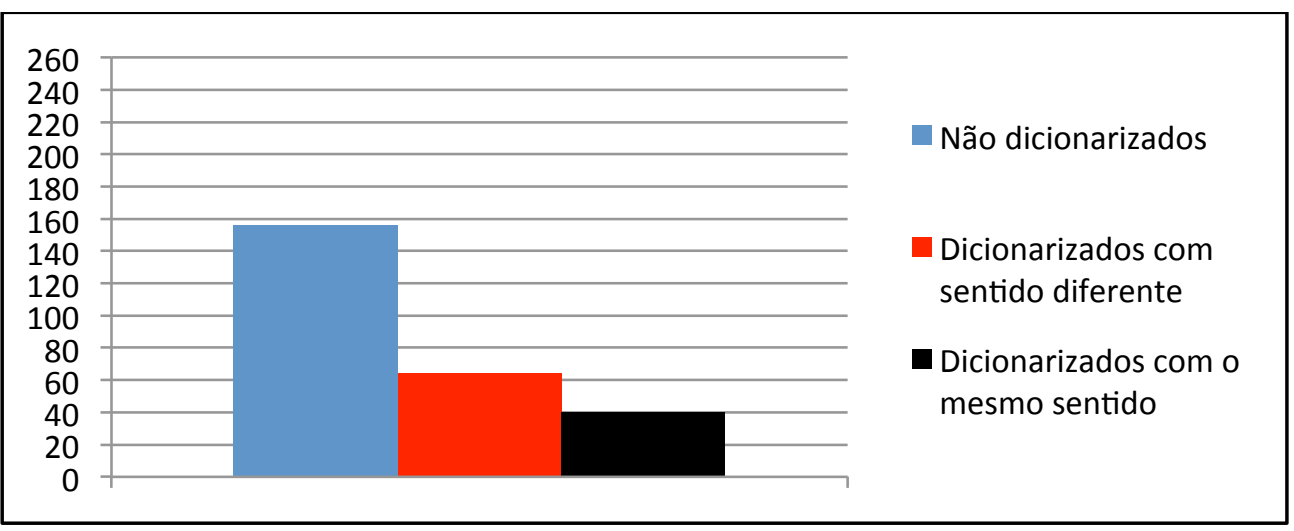

Fonte: Elaboração do autor

Assim, após a transcrição das entrevistas e a subsequente análise dos termos e expressões utilizados, foi possível constatar que os dois grupos que representaram o fator social 'grau de escolarização' apresentaram alguns itens lexicais específicos de seu grupo, quando comparado ao outro grupo. O grupo constituído por adolescentes que tinham cursado até o sexto ano do Ensino Fundamental permitiu uma a obtenção dos seguintes termos e expressões: 'bic', 'cagão', 'cheio de querer', 'calçado', 'chamar na humildade', 'chapar com', 'chorar', 'desacorçoado', 'em choque', 'viado', 'isqueiro', 'pazinha', 'peidão', 'pegar pira', 'tinteira', 'perna', 'tô lesado', 'tô no veneno'.

A coleta de dados com os adolescentes que estavam cursando anos posteriores ao sexto ano do Ensino Fundamental também apresentou itens lexicais utilizados somente pelos seus integrantes, como os termos: 'agá', 'atrasa-lado', 'banha', 'gancha', 'beca', 'fire', 'burrão', 'calçar o peito', 'calibre', 'calibrado', 'camito', 'cisco', 'cincão', 'contenção', 'dar atenção','dar uma mão', 'desavença', 'desco', 'deizão', 'rolon', 'embalo', 'encaixotar', 'estar no sossego', 'naifa', 'Falseane', 'fechar com alguém', 'fino', 'onça', 'guento', 'inocentão', 'lance', 'licença com a palavra', 'pó', 'veste', 'passar a visão', 'passar o fone', 'piolho', 'Qual seu B. O.?', 'estampa', 'tá suave', 'tô de lara', 'tongo'.

Uma das duas possivieis explicações para essa diferença de usos linguísticos exclusivos em relação a essas duas variáveis está relacionada com as proposições contidas nos Parâmetros Curriculares Nacionais (BRASIL, 1998) relativas ao terceiro e quarto ciclos do Ensino Fundamental e à disciplina de Língua Portuguesa, que prescrevem uma revisão do ensino nas escolas brasileiras a fim de desenvolver a competência comunicativa dos 
alunos, ao invés de meramente mostrar-lhes regras gramaticais. Para isso, orientam que os professores façam uso dos variados gêneros textuais gradativamente, pois além de contemplarem as formas linguísticas orais e escritas e abrangerem tanto a variante padrão quanto a não-padrão da Língua Portuguesa, eles trazem uma série de textos que possuem determinadas características que representam variadas situações sociocomunicativas, justamente com o objetivo de ampliar o repertório linguístico dos alunos e prepará-los para as diversas situações discursivas do dia-a-dia. Assim, o contato com variados gêneros textuais pode ter sido o responsável por esses usos linguísticos específicos de termos com sentido figurado pelo grupo que representou a variável 'nível de escolarização superior ao sexto ano do E. F.'

Por outro lado, os termos e expressões com sentido figurado obtidos, especificamente, através da variável 'nível de escolarização de até o sexto ano do E, F.' podem estar relacionados ao fato de que todos os integrantes do grupo que representou essa variável apresentaram grande defasagem escolar, o que pode indicar que tal defasagem pode ter sido a responsável pelo repertório linguístico obtido, em virtude do escasso contato com gêneros textuais, por ocasião de estarem cursando anos iniciais do E. F.

Tal defasagem tem como uma das causas o fato de muitos adolescentes internados apresentarem vários episódios de interrupção do processo de aprendizagem escolar em virtude de terem sido privados de liberdade, via condenação judicial, devido aos atos infracionais praticados. Nesse sentido, os dados do IPEA - Nota Técnica (DA SILVA; DE OLIVEIRA, 2015) apontam como uma das principais causas dessa defasagem escolar a extrema condição de pobreza em que vivem esses menores e demonstram que dois terços dos adolescentes que cumprem medidas socioeducativas vêm de famílias extremamente desprovidas das mínimas condições de subsistência, em que a fome, a carência de recursos materiais e a penúria social e econômica favorecem tais adolescentes a procurar meios, muitas vezes ilícitos, de lutar pela sobrevivência, fato que colabora para o fenômeno do abandono escolar. 
A influencia de fatores sociais na linguagem de adolescentes privados de liberdade | Rodrigo Mazer Etto, Valeska, Gracioso Carlos

Soma-se a esse quadro o fato de que muitos deles passem a frequentar regularmente uma escola somente a partir do momento em que ingressam no CENSE, haja vista que, quando em liberdade, muitos não apresentavam assiduidade ao ambiente escolar.

Com relação ao fator social 'convívio' trabalhava-se com a hipótese que os internos residentes em alojamentos em que o convivio era permitido utilizassem formas linguísticas com sentido figurado distintas das utilizadas pelos internos residentes em alojamentos sem possibilidade de convívio, devido à possibilidade de trocas linguísticas mais intensas, proporcionadas pela maior interação entre os alojados.

Através das análises dos usos linguísticos específicos dos dois grupos que representaram as variáveis 'possibilidade de convivio' e 'não possibilidade de convivio', foi possivel constatar que a primeira permitiu a obtenção dos seguintes itens lexicais: 'banha', 'bater a blindada', 'gancha', 'burrão', 'cagueta', 'caçamba', 'cagão', 'calçado', 'calçar o peito', 'calibrado', 'camito', 'chapar com', 'chocar', 'catatau', 'cisco', 'dar atenção', 'dar uma mão', 'desacorçoado', 'desavença', 'desco', 'doze-duque', 'embalo', 'encaixotar', 'estar no sossego', 'falseane', 'faraó', 'fechar com alguém', 'fino', 'gancha', 'pelota', 'onça', 'graxa', 'licença com a palavra', 'mascão', 'pó', 'veste', 'passar a visão', 'passar o fone', 'pazinha', 'peidão', 'pegar pira', 'perna', 'piolho', 'procedimento', 'tá suave', 'tô de lara', 'tongo'.

A segunda variável, representada pelos internos residentes em alojamentos sem possibilidade de convívio, permitiu a obtenção de outros termos e expressões somente utilizadas pelos seus integrantes, como: 'beca', 'calibre', 'cheio de querer', 'chamar na humildade', 'cincão', 'deizão', 'em choque', 'viado', 'inocentão', 'isqueiro', 'magar', 'mandar um salve', 'tinteira', 'estampa', 'tô lesado', 'tô no veneno'.

Uma das prováveis razões para o uso de itens lexicais específicos por cada um dos dois grupos tem por base o estudo de Remenche (2003), realizado nas Unidades Prisionais de Londrina e Curitiba, em que foi constatado que, após um período de tempo lotados em celas individuais (período de observação), os sentenciados adultos recém-chegados eram transferidos para celas coletivas, que contavam com a média de 20 a 30 
pessoas, sendo que seus comportamentos, tanto o linguístico, quanto o relacionado às vestimentas e determinadas posturas, mudavam depois de um período de tempo convivendo com outros sentenciados, apresentando uma linguagem com maior uso de termos e expressões com sentido figurado, a gíria.

A pesquisa de Remenche (2003) comprova esse argumento, que tem como fundamento o fato de que indivíduos privados de liberdade tendem a procurar meios de minimizar os efeitos negativos da segregação social, do afastamento do convivio familiar, da restrição de circulação e da sensação de estar sob constante vigilância, através de um compartilhamento de valores e regras paralelas, dentre elas o uso comum de uma linguagem peculiar, a gíria de grupos ligados à marginalidade.

Nesse sentido, é possível inferir que a concentração das relações sociais dentro de uma rede social (alojamento) concorre para o desenvolvimento do sentimento de pertencer a uma mesma identidade local, construída através da relativa homogeneidade de comportamento - no vestir, no falar e no pensar (ECKERT, 2000), pois segundo Evans (2004), as redes sociais são consideradas como teias de laços que se estendem, potencialmente a todos a pessoas que comumente interagem entre si, sendo ancoradas nos indivíduos.

Dessa forma, os resultados obtidos relacionam-se com o fato da possibilidade de maior interação entre os membros de um mesmo alojamento influenciar e estimular um uso linguístico específico de itens com sentido figurado, devido à maior interação entre os adolescentes nele alojados, pois há a possibilidade de relacionarem-se linguisticamente com mais intensidade e, nessa maior interação, os indivíduos influenciam uns aos outros, onde processos simbólicos e relações identitárias diversas têm lugar. O sentimento de pertencimento a um grupo, propiciado pela rede social que o compõe, possibilita que seus integrantes se conheçam mais profundamente, integrando, nas palavras de Milroy (1980), uma rede social densa e quase sempre multiplexa, que sustenta e explica a emergência de variantes vernaculares de uso comum. 
A influencia de fatores sociais na linguagem de adolescentes privados de liberdade | Rodrigo Mazer Etto, Valeska, Gracioso Carlos

Portanto, há uma maior possibilidade de trocas linguísticas mais intensas, constatação que se apoia em Labov (2010), quando este discute os fatores sociais que, em seu conjunto, dirigem o processo de mudança linguística, reconhecendo ser a rede social uma das forças motrizes do uso de variedades linguísticas pela capacidade de dar relevo ao indivíduo no processo de mudança.

Assim, é possivel concluir que nos alojamentos em que há a possibilidade de interação, proporcionada pela rede social dos seus residentes, a variação é usada para evocar uma identificação ao grupo de residentes da casa, sendo que, desse modo, as formas linguísticas adquirem valor social, o que acaba por influenciar seus comportamentos linguísticos, com tendência a apresentar, particularmente, termos e expressões com sentido figurado em relação aos residentes em alojamentos onde o convívio não é permitido nem possível.

Como a presente pesquisa teve como foco a influência de três fatores sociais, outros fatores não escolhidos podem também ter influenciado nos usos linguísticos dos dois grupos, pois, conforme Naro (2004): as diversas categorias que são representadas por diferentes fatores sociais se apresentam comumente conjugadas e inter-relacionadas, o que denota que a existe uma influência simultânea dos vários fatores sociais que incidem sobre as variações linguísticas.

Ao eleger o fator 'tempo de internação' para a nossa pesquisa, considerava a hipótese de que um maior tempo de privação de liberdade e o consequente maior tempo exposto às características do CENSE e às influências dos outros internos fossem responsáveis por usos específicos de termos e expressões de sentido figurado.

Essa hipótese inicial se concretizou, visto que a variável 'tempo de internação de até seis meses' possibilitou a identificação dos seguintes itens: 'atrasa-lado', 'burrão', 'caçamba', 'cheio de querer', 'chamar na humildade', 'cisco', 'dar uma mão', 'desco', 'em choque', 'rolon', 'Falseane', 'faraó', 'viado', 'galeto', 'prestobarba', 'graxa', 'isqueiro', 'licença com a palavra', 'veste', 'garoup', 'tinteira', 'tô lesado', 'tô no veneno'. 
O grupo que representou a variável 'tempo de internação superior a seis meses' permitiu a obtenção dos seguintes termos: 'agá', 'banha', 'gancha', 'beca', 'caçamba', 'cagão', 'calçado', 'chapar com', 'chorar', 'cincão', 'contenção', 'dar atenção', 'desacorçoado', 'desavença', ‘deizão', 'doze-duque', 'embalo', 'estar no sossego', 'naifa', 'fechar com alguém', 'inocentão', 'lance', 'mascão', 'na rocha', 'pazinha', 'caiçara', 'peidão', 'pegar pira', 'perna', 'piolho', 'procedimento', 'estampa'.

Essa diferença de usos linguísticos entre os dois grupos pode estar relacionada ao perfil dos integrantes que compuseram cada grupo que representou as duas variáveis, pois a variável 'tempo de internação de até seis meses' foi representada por quatro adolescentes com os seguintes períodos de cumprimento de medidas socioeducativas privativas de liberdade: um estava cumprindo dois meses e meio de tais medidas, um estava cumprindo tais medidas há cinco meses e dois se encontravam nessa condição por um período de seis meses. A outra variável foi representada por dois adolescentes que estavam há sete meses cumprindo medida de internação, um adolescente que cumpria um período total de internação de dois anos e outro que totalizava quatro anos de cumprimento de tais medidas.

Assim, a proximidade (e baixa diferença) de períodos de internação entre os participantes dos dois grupos pode ter sido a responsável pela diferença de uso de termos e expressões com sentido figurado, praticadas exclusivamente por cada grupo.

Uma das explicações para essa diferença de usos linguísticos pode estar relacionada ao fato de que, dos quatro integrantes do grupo composto por internos com grau de escolarização de até seis meses, somente um adolescente tinha passado por outras unidades de internação - Foz do Iguaçu e Cascavel, sendo que os demais componentes desse grupo estavam cumprindo medidas de privação de liberdade apenas no CENSE de Ponta Grossa. Dessa forma, é possível verificar que somente esse elemento desse grupo não foi influenciado por características ambientais de outro CENSE, nem sofreu influência do contato com internos de outras unidades. 
A influencia de fatores sociais na linguagem de adolescentes privados de liberdade | Rodrigo Mazer Etto, Valeska, Gracioso Carlos

Por outro lado, todos os adolescentes do grupo que representou a variável 'tempo de internação superior a seis meses' já tinham passado por outras unidades socioeducativas, localizadas nas cidades de Curitiba, Cascavel, Foz do Iguaçu e Maringá, sendo que esses períodos maiores de tempo interagindo com adolescentes oriundos de várias cidades do Paraná em outras unidades podem ter colaborado para o desenvolvimento de um comportamento linguístico com a presença exclusiva de alguns itens lexicais com sentido figurado, quando comparado ao grupo que representou a outra variável.

Vale a pena esclarecer que, além das características físicas e socioculturais de uma unidade prisional e de um CENSE serem muito parecidas, os valores e ideias dos dois grupos sociais que neles se encontram (população carcerária e população de adolescentes internos) também são muito similares, no sentido de apresentarem uma cultura de enfrentamento e oposição às normas de convivência e aos valores defendidos pela sociedade.

Essa relação entre uso linguístico e influência da comunidade de falantes pôde ser verificada no dia a dia de uma unidade prisional, em que foi possivel constatar que quanto mais tempo um sentenciado era submetido ao contato com outros internos, maior era a sensação de pertencimento a esse grande grupo social e maior era a necessidade de impor diferenças entre o grupo a que pertence e a sociedade, sendo visivel a mudança comportamental e linguística dos recém-chegados com o passar do tempo e, devido ao contexto de privação de liberdade que caracteriza uma penitenciária e um CENSE, tal influência também é passível de ser verificada no último. Esse argumento encontra respaldo em Preti (1984), quando este aponta que os membros de um grupo fechado procuram, através de certos usos linguísticos, estabelecer diferenças entre o meio social em que vivem e a sociedade. Esse autor acrescenta que tal grupo o faz como um mecanismo de defesa, constituindo-se em uma atitude característica de grupos ligados à marginalidade, sendo que a tendência ao isolamento desses grupos termina por provocar a adoção de uma linguagem peculiar. 
A influencia de fatores sociais na linguagem de adolescentes privados de liberdade | Rodrigo Mazer Etto, Valeska Gracioso Carlos

O maior tempo de internação, submetido às características de uma instituição fechada - como a segregação social; afastamento familiar; submissão à vigilância dos funcionários e das câmeras de segurança - com a consequente falta de privacidade; a obrigação de conviver com internos com variados históricos de vida ligados à violência e a sujeição às normas institucionais e às paralelas também pode resultar em uma maior necessidade de se adquirir um comportamento comum aos demais, tanto o relacionado ao compartilhamento de valores e regras paralelas, quanto ao comportamento linguístico, considerando-se que a linguagem comumente praticada no CENSE é constituída de palavras com sentido figurado, diferente da usual.

Nesse sentido, é pertinente destacar o apontamento de Remenche (2003) que, na sua dissertação de mestrado, realizou uma pesquisa com temática semelhante envolvendo sentenciados adultos e apontou que essa variedade linguística, a gíria de grupo ou marginal, está relacionada à influência do ambiente físico e sociocultural em que é praticada, sendo esses elementos suficientes para marcar a linguagem desse grupo que, da mesma forma que os adolescentes internos de um CENSE, também é estigmatizada pela sociedade, o que contribui para que essas comunidades minoritárias, em conflito com o meio social em que vivem, hermetizem-se de maneiras diversificadas e adquiram um comportamento similar: tanto no uso de tatuagens e no compartilhamento de ideias e valores, quanto na linguagem, no sentido de uma prática linguística de uso comum, identificadora de tal grupo social.

\section{CONSIDERAÇÕES FINAIS}

A análise e a identificação dos sentidos do léxico que compõe a linguagem praticada pelos internos do CENSE permitem concluir que essa variedade linguística, também conhecida como gíria de grupo, é dinâmica, figurada e reflete o comportamento social dos indivíduos que a praticam, expressando seus sentimentos, pensamentos, emoções e desejos.

A classificação em nove campos conceituais e a análise do significado dos termos e expressões coletados possibilitaram concluir que essa 
A influencia de fatores sociais na linguagem de adolescentes privados de liberdade | Rodrigo Mazer Etto, Valeska, Gracioso Carlos

variedade linguística tem como característica uma tendência à concretização das ações, dos objetos e situações que compõem o ambiente fechado de internação do CENSE, através da utilização de palavras com sentido diferente daquele registrado em dicionários, no intuito de serem somente compreendidas por quem faz parte desse grupo de falantes.

Os aportes teóricos de Sapir (1971 [1921]), como o que se fundamenta na relação entre língua e cultura, e que considera a linguagem como uma função cultural, direcionaram esse trabalho, no sentido de destacar a cultura de enfrentamento e oposição dos internos da instituição à sociedade civil - que se manifesta através da adoção de uma linguagem com sentido figurado, pois, para se compreender o comportamento linguístico desses adolescentes foi necessário conhecer o grupo social em questão, com seus valores e aspectos socioculturais.

Outro fundamento de Sapir (1987 [1947]) que direcionou essa pesquisa foi o que se baseia na relação entre ambiente e linguagem, visto que, propiciou a compreensão de que o contexto físico e socioambiental do CENSE também influencia nas escolhas lexicais dos falantes da instituição, sendo as principais características desse ambiente: a restrição de circulação, o afastamento do convivio familiar, a obediência às regras institucionais internas e às normas paralelas impostas pela população geral, a convivência forçada entre adolescentes com histórico de vidas diversos ligados à violência e a sensação constante de estar sob vigilância eletrônica e do corpo funcional.

A dimensão social da linguagem proposta por Coseriu (1982), que considera a linguagem intimamente relacionada àquilo que os interlocutores têm em comum, fundamentou o conceito de língua utilizado, considerando que a mesma não é algo que se apresenta pronta e que os internos têm em comum vários aspectos, como estarem segregados da convivência social, a obediência às regras institucionais e paralelas e terem vivenciado situações e praticado ações ligadas à violência.

O conceito de norma de Coseriu (1987), definida como uma sequência de manifestações obrigatórias e de imposições socioculturais, e como um conjunto de realizações concretas de caráter coletivo, embasou a 
interpretação e classificação das duas variantes linguísticas praticadas no CENSE, a de sentido figurado e a de sentido comum.

Os fundamentos da Sociolinguística Laboviana (LABOV, 1983, 2008 [1972]), principalmente o que diz respeito à heterogeneidade presente em todas as linguas, permitiram constatar que alguns fatores extralinguísticos podem influenciar e contribuir para o maior ou menor uso de uma linguagem caracterizada pela presença de palavras com sentido figurado, que constitui-se em uma variação semântico-lexical proporcionada pela heterogeneidade linguística.

Paralelamente, a análise da relação entre as seis variáveis utilizadas e os itens lexicais utilizados exclusivamente por cada um dos dois grupos que representaram cada fator social possibilitou os seguintes apontamentos:

- O maior tempo exposto às influências ambientais e culturais do CENSE e da população de internos possibilitou que, através da variável 'tempo de internação superior a seis meses', se obtivesse itens lexicais utilizados exclusivamente pelos integrantes do grupo que representou essa variável.

- O menor tempo de permanência em instituições socioeducativas, somado à impossibilidade de uma maior identificação como um membro da comunidade formada por toda a população de internos do CENSE - que dificulta o compartilhamento de ideias e valores (inclusive da linguagem) - possibilitou a identificação de outros termos e expressões com sentido figurado, exclusivamente utilizados pelos internos que representaram a variável 'tempo de internação de até seis meses'.

- O contato com variados gêneros textuais no ambiente escolar, que favorece a ampliação do repertório vocabular do falante, possibilitou a obtenção de alguns itens lexicais com sentido figurado utilizados exclusivamente pelos integrantes do grupo com 'nível de escolarização superior ao sexto ano do EF'. 
A influencia de fatores sociais na linguagem de adolescentes privados de liberdade | Rodrigo Mazer Etto, Valeska, Gracioso Carlos

- O pouco contato com vários gêneros textuais, que possibilitariam um aumento do repertório linguístico do falante, somado à defasagem escolar que caracterizou todos os elementos do grupo com menor tempo de escolaridade, permitiu a identificação de outros itens lexicais com sentido figurado, usados especificamente pelos adolescentes que representaram a variável 'nível de escolarização até o sexto ano do EF'.

- A formação de uma rede social entre os internos residentes em um mesmo alojamento permitiu a obtenção de termos e expressões com sentido figurado, utilizadas particularmente pelo grupo que representou a variável 'possibilidade de convivio'.

- A impossibilidade de formação de uma rede social nos alojamentos em que o convívio entre os seus residentes não é permitido possibilitou a obtenção de outros itens lexicais exclusivamente utilizados pelos adolescentes que representaram a variável 'não possibilidade de convivio'.

Certamente, outros fatores não observados nessa pesquisa também podem contribuir para o uso dessa variedade linguística, mas o caráter sincrônico, a perspectiva etnográfica, o número e a característica dos participantes, e o perfil dos internos que a instituição comporta favoreceram a utilização desses três índices de enquadramento social. Assim, fatores sociais como 'idade' e 'sexo' dos falantes adolescentes também se apresentam importantes, mas o perfil dos internos do CENSE de Ponta Grossa não permitiu o estudo desses fatores extralinguísticos.

O presente trabalho apresentou algumas limitações, como por exemplo, o limitado número de colabores, considerando que Labov (1983) recomenda contar com o mínimo de 25 participantes em um estudo sociolinguístico, mas a autorização concedida pela direção do CENSE só nos permitiu entrevistar oito adolescentes. Outra limitação se refere ao tempo concedido para a realização das entrevistas, pois, se fosse possível um maior tempo para a plicação da entrevista semiestruturada, um maior número de termos e expressões poderiam ter sido obtidos, o que, provavelmente 
A influencia de fatores sociais na linguagem de adolescentes privados de liberdade | Rodrigo Mazer Etto, Valeska Gracioso Carlos

permitiria uma análise mais abrangente do léxico utilizado pelos adolescentes.

Este trabalho pode contribuir para reforçar o entendimento de que as variedades linguísticas são consequência da heterogeneidade das línguas e são produto de fatores internos e externos ao sistema linguístico, levando-se em conta que existem aqueles que defendem que a melhor maneira de falar é aquela oriunda da norma padrão, e outros que acreditam que existem ocasiões que permitem o uso de variantes de menor prestígio. Segundo Bagno (2004), os primeiros favorecem a ocorrência de atitudes de discriminação e preconceito linguístico, pois defendem a existência de uma única forma de falar, a padronizada.

A variedade linguística usada pelos adolescentes em cumprimento de medidas socioeducativas de privação de liberdade está longe de ser somente uma questão de prestígio ou não, pois essas variações possibilitam maior liberdade na comunicação, sendo utilizadas no sentido de possibilitar mais segurança ao falante e um sentimento de pertencimento a determinado grupo.

O crescente número de adolescentes cumprindo medidas socioeducativas de internação, com o consequente aumento da população carcerária brasileira, não se constitui apenas em uma questão de segurança, mas também exige que seja tratado de maneira multissetorial, não somente por autoridades policiais, juristas, psicólogos e assistentes sociais, mas tendo a participação de outros profissionais, como o pesquisador sociolinguista, que, ao pesquisar a linguagem desses adolescentes pode trazer à tona questões sobre o uso desse código linguístico no trabalho pedagógico, na atenção básica à educação, bem como sobre as estratégias didáticas e pedagógicas para promover o desenvolvimento de competências escolares que envolvam o processo educacional e a linguagem praticada por tal grupo social.

É nesse sentido que a presente pesquisa pretende contribuir para os estudos sociolinguísticos no sentido de possibilitar a criação de ferramentas pedagógicas que auxiliem tanto o processo de ensino-aprendizagem escolar desses adolescentes, quanto a desconstrução do preconceito linguístico, o 
A influencia de fatores sociais na linguagem de adolescentes privados de liberdade | Rodrigo Mazer Etto, Valeska, Gracioso Carlos

qual acaba por reforçar a posição social (marginal) desses adolescentes, pois é preciso considerar que estes, se não forem assistidos no tocante à educação escolar e não receberem uma atenção especial por parte de educadores e das demais pessoas que lidam com esse grupo social, futuramente terminarão por engrossar o número de sentenciados nas penitenciárias brasileiras, como tem acontecido regularmente nas últimas décadas segundo os dados mais recentes do INFOPEN (BRASIL, 2017).

As investigações entre linguagem e fatores extralinguísticos e sua relação com o comportamento social dos falantes podem contribuir para a compreensão do universo vocabular dos adolescentes que cumprem medidas socioeducativas, e colaborar com as práticas daqueles que trabalham com jovens, buscando compreender melhor suas particularidades, com a finalidade de auxiliá-los e conduzi-los nessa constante busca de experimentação de novas sensações e de tudo que se apresenta como novo.

\section{REFERÊNCIAS}

BAGNO, Marcos. Nada na língua é por acaso: por uma pedagogia da variação linguística. São Paulo: Parábola Editorial, 2007.

BAKHTIN, Mikhail. Marxismo e Filosofia da Linguagem: problemas fundamentais do Método Sociológico na Ciência da Linguagem. Tradução de Michel Lahud e Frateschi Vieira. 12 ${ }^{\mathrm{a}}$ edição. São Paulo: Hucitec, 2006.

BORTONI-RICARDO, Stella Maris. Educação em língua materna: a sociolinguística na sala de aula. São Paulo: Parábola Editorial, 2004.

BRASIL. Ministério da Educação. Parâmetros curriculares nacionais: terceiro e quarto ciclos do ensino fundamental: lingua portuguesa. Brasília: MEC/SEF, 1998.

Ministério da Justiça. Departamento Penitenciário Nacional. Levantamento Nacional de Informações Penitenciárias - INFOPEN. Dezembro, 2017. Disponivel em <https://www.poder360.com.br/wpcontent/uploads/2017/12/relatorio_2016_Junho.pdf>. Acesso em 19 de janeiro de 2017 .

- Presidência da República. Secretaria de Direitos Humanos da Presidência da República (SDH). Levantamento Anual SINASE 2014. Brasília: 2015a. 
Ministério da Justiça. Conselho Nacional de Justiça. Cadastro Nacional de Adolescentes em Conflito. Brasília, 2016.

COELHO, Lidiane. Pereira; MESQUITA, Diana Pereira Coelho de. Língua, cultura e identidade: conceitos intrinsecos e interdependentes. EntreLetras, v. 4 , n. 1, 2013.

COSERIU, Eugenio. Teoria da linguagem e lingüistica geral. $2^{a}$ edição. Rio de Janeiro: Presença, 1987.

DA SILVA, Enid Rocha Andrade; DE OLIVEIRA, Raíssa Menezes. Nota Técnica $n^{\circ}$ 20. $O$ adolescente em Conflito com a Lei e o Debate sobre a Redução da Maioridade Penal: esclarecimentos necessários. 43 p., 2015. Disponivel em <http://www.maioridadepenal.org.br/arquivos/Nota\%20t\%C3\%A9cnica\%20

\%20O\%20Adolescente\%20em\%20Conflito\%20com\%20a\%20Lei\%20e\%20o\%2 0Debate\%20sobre\%20a\%20Redu\%C3\%A7\%C3\%A3o\%20da\%20Maioridade\% 20Penal.pdf>. Acesso em 01 de janeiro de 2018.

EAGLETON, Terry. A ideia de cultura. São Paulo: Unesp, 2005.

ECKERT, Penelope. Linguistic variation as social practice. Malden/Oxford: Blackwell, 2000.

EVANS, Betsy. The role of social network in the acquisition of local dialect norms by Appalachian migrants in Ypsilanti, Michigan. Language Variation and Change, Cambridge, V. 16, p.153-167, julho 2004.

FARACO, Carlos Alberto. A Linguagem e o Homem. In: Linguagem e sociedade. FARACO, C. A \& FLORIANE, D. (org.). Curitiba. SECE/Biblioteca Pública do PR, 1985.

Norma culta brasileira: desatando alguns nós. São Paulo: Parábola Editorial, 2008.

FLICK, Uwe. Introdução à metodologia de pesquisa: um guia para iniciantes. Tradução Magda Lopes. Porto Alegre: Penso, 2013.

HOUAISS, Antônio; VILLAR, Mauro de Salles. Dicionário Houaiss Conciso. São Paulo: Moderna, 2011.

JOHNSTONE, Barbara. Qualitative methods in sociolinguistics. New York: Oxford University Press, 2000.

LABOV, William. Principles of linguistic change - social factors. Oxford: Blackwell, [1972] 2001. 
A influencia de fatores sociais na linguagem de adolescentes privados de liberdade | Rodrigo Mazer Etto, Valeska, Gracioso Carlos

Padrões sociolinguísticos. Tradução Marcos Bagno, Maria Marta Pereira Scherre e Caroline Rodrigues Cardoso. São Paulo: Parábola Editorial, [1972] 2008, 391p.

Principles of linguistic change: cognitive and cultural factors. Malden/Oxford/Sussex: Wiley-Blackwell, 2010.

LOPES, Adriana Carvalho. Narrativas das adolescentes em conflito com a Lei. 2003. 199 f. Dissertação (Mestrado em Linguística, Linguas Clássicas e Vernáculas) - Universidade de Brasília, Brasília.

LÜDKE, Menga; ANDRÉ, Marli. Pesquisa em educação: abordagens qualitativas. São Paulo: EPU, 1986.

MILROY, Lesley. Language and social networks. Oxford: Blackwell, 1980.

NARO, Anthony Julius. Idade. In: MOLLICA, Maria Cecília; BRAGA, Maria Luiza (Orgs.). Introdução à sociolinguistica - o tratamento da variação. São Paulo: Contexto, 2004.

POSSENTI, S. Por que (não) ensinar gramática na escola. Campinas: Mercado de Letras, 1997.

PRETI, Dino. A giria e outros termos. São Paulo: T.A. Queiroz Edusp, 1984.

REMENCHE, Maria de Lourdes Rossi. As criações metafóricas na gíria do sistema penitenciário do Paraná. 2003. 107 f. Dissertação (Mestrado em Estudos da Linguagem) - Universidade Estadual de Londrina, Londrina.

SAPIR, Edward. A linguagem: introdução ao estudo da fala. $2^{a}$ edição. Rio de Janeiro: Livraria Acadêmica, [1921] 1971.

Linguística como ciência: uma introdução. Rio de Janeiro: Livraria Acadêmica, 1987 [1947].

TARALLO, Fernando. A pesquisa sociolinguistica. São Paulo: Ática, 2003.

VOTRE, Sebastião Josué. Relevância da variável escolaridade. In: MOLLICA, Maria Cecília; BRAGA, Maria Luiza (Orgs.). Introdução à Sociolinguística: o tratamento da variação. São Paulo: Contexto, 2004, p. 51-57.

WEINREICH, Uriel; LABOV, William; HERZOG, Marvin. Fundamentos empiricos para uma teoria da mudança linguistica. Parábola, [1968] 2006. 